\title{
Analisis Skala Usaha Dan Finansial Usahatani Kopi Arabika (Coffea arabica) Di Kabupaten Gayo Lues
}

\author{
Reny Meisetyani 1 \\ Indra $2^{*}$ \\ Syakur 3 \\ ${ }^{1}$ Mahasiswa Program Magister Konservasi Sumberdaya Lahan, Universitas Syiah Kuala \\ 2Program Studi Agribisnis, Universitas Syiah Kuala \\ ${ }^{3}$ Program Studi Ilmu Tanah, Universitas Syiah Kuala \\ *email : indrazainun@unsyiah.ac.id \\ Diterima: Januari 2021; Disetujui: September 2021; Dipublish: Oktober 2021
}

\begin{abstract}
Abstrak
Kopi Arabika yang ada di Kabupaten Gayo Lues masih sangat berpotensi untuk dikembangkan. Dengan luasan pengembangan kopi yang cukup besar, dan merupakan salah satu kopi dengan cita rasa terbaik di dunia serta pangsa pasar yang menjanjikan dapat menjadi mata pencaharian dan meningkatkan pendapatan serta kesejahteraan para petani. Tujuan penelitian ini adalah skala usaha dan finansial usaha tani kopi Arabika pada kelas kesesuaian lahan di Kabupaten Gayo Lues. Penelitian dilaksanakan di Kabupaten Gayo Lues, dengan metode penelitian deskriptif yaitu metode penelitian dalam meneliti data-data yang dikumpulkan, disusun, dijelaskan, serta dianalisis. Metode pengambilan sampel dilakukan secara purposive sampling dengan jumlah data yang diambil Petani sebanyak 45 responden serta Pedagang sebanyak 10 responden. Hasil penelitian dengan luas lahan 0,49 ha atau 4.864,96 $\mathrm{m}^{2}$ petani kopi arabika sudah mencapai titik impas dalam mengusahakan usahataninya. Dengan produksi kopi arabika sebesar 920,29 kg/tahun maka petani sudah pulang pokok pada produksi. Dengan harga Rp. 17.243,59 per kg petani sudah bisa menutupi semua biaya yang dikeluarkan untuk usahatani kopi arabika. Selanjutnya pada tingkat suku bunga sebesar $12 \%$ nilai Net B/C > 0 yaitu sebesar 2,24 artinya, setiap satu rupiah yang dikeluarkan selama umur usaha menghasilkan Rp. 2,24 satuan manfaat bersih.
\end{abstract}

Kata Kunci : Kopi Arabika, Skala Usaha, Kelayakan, BEP

\begin{abstract}
Arabica coffee in Gayo Lues Regency has the potential to be developed. With a large area of coffee development, and is one of the best tasting coffees in the world and a promising market share, it can be a source of livelihood and increase the income and welfare of farmers. The purpose of this study was the scale of the business and finance of Arabica coffee farming in land suitability classes in Gayo Lues Regency. The research was conducted in Gayo Lues Regency, with a descriptive research method, namely the research method in examining the data that was collected, compiled, explained, and analyzed. The sampling method was purposive sampling with the amount of data taken by farmers as many as 45 respondents and traders as many as 10 respondents. The results of the study with a land area of 0.49 ha or 4,864.96 $\mathrm{m} 2$ Arabica coffee farmers have reached the break-even point in cultivating their farming. With Arabica coffee production of $920.29 \mathrm{~kg} /$ year, the farmers have returned to the main production. With a price of Rp. 17,243.59 per $\mathrm{kg}$ of farmers can cover all the costs incurred for farming Arabica coffee. Furthermore, at an interest rate of $12 \%$, the Net $B / C$ value $>0$ is 2.24, meaning that every one rupiah spent during the business period generates $R p$. 2.24 unit of net benefit.
\end{abstract}

Keywords: Arabica Coffee, Business Scale, Feasibility. 


\section{PENDAHULUAN}

Kopi merupakan salah satu komoditas andalan dalam sektor perkebunan Indonesia. Sebagian besar ekspor kopi Indonesia adalah jenis Kopi Robusta (94\%), dan sisanya adalah kopi jenis arabika. Sedangkan, konsumsi kopi dunia mencapai $70 \%$ berasal dari spesies Kopi Arabika dan 26\% berasal dari Kopi Robusta. Hal ini menunjukkan bahwa sebenarnya peluang pasar Kopi Arabika lebih besar dibandingkan Kopi Robusta (Kusmiati \& Nursamsiyah, 2015).

Kopi arabika merupakan jenis kopi dengan cita rasa terbaik dan komoditi unggulan yang memiliki nilai ekonomi relatif tinggi di pasar dunia. Dengan ketinggian tempat atau elevasi antara $329-1.458 \mathrm{mdpl}$ yang mana pada ketinggian tersebut tanaman kopi arabika dapat tumbuh dengan baik (Arlius et al., 2017).

Kopi Arabika Gayo merupakan salah satu kopi terbaik di Indonesia yang mendunia. Adanya karakter cita rasa yang khas pada kopi Arabika Gayo sebagai produk kopi spesialti (Mawardo et al., 2008). Di Kabupaten Gayo Lues telah berkembang kopi Arabika seluas 3.654,56 hektar dari luas lahan berpotensi sekitar 80.212,83 hektar (Karim et al., 2020).

Indikasi Geografis (IG) Kopi Arabika Gayo adalah suatu tanda yang menunjukkan daerah asal kopi Arabika Gayo. Wilayah Indikasi Geografis (IG) Kopi Arabika Gayo di Dataran Tinggi Gayo yang sesuai dengan ketinggian tempat di atas permukaan laut adalah $160.856,70$ ha. Wilayah IG Kopi Arabika Gayo yang sesuai dengan kawasan yang telah ditetapkan sebagai kawasan budidaya di dalam Rencana Tata Ruang Wilayah (RTRW) Kabupaten Bener Meriah, Aceh Tengah dan Gayo Lues adalah seluas 151.151,60 ha (Ellyanti et al., 2012).

Dampak perubahan iklim, mempengaruhi aspek yang berkaitan dengan budidaya kopi. Termasuk produksi, produktivitas, kualitas hasil dan pendapatan petani kopi arabika (Widayat et al., 2015). Meningkatkan Produktivitas hasil kopi dapat dilakukan dengan kegiatan pemangkasan bentuk dan pemangkasan produksi (pemeliharaan). Produktivitas tanaman kopi yang dipangkas secara rutin lebih besar dibandingkan dengan tanaman kopi yang tidak dilakukan pemangkasan secara rutin, sehingga pendapatan yang diperoleh petani yang melakukan pemangkasan secara rutin lebih tinggi dibandingkan dengan petani yang tidak melakukan pemangkasan secara rutin. (Zulkarnain et al., 2020).

Selain dilakukan pemangkasan, Strategi adaptasi bagi petani di dataran tinggi adalah dengan menjaga kerapatan tanaman kopi serta kerapatan naungan pada tingkat yang optimal, diikuti dengan peningkatan praktek pengelolaan seperti pemangkasan, penyiangan, pemberian pupuk, dan pengendalian hama dan penyakit (Anhar et al., 2020). 
Menurut (Izzati et al., 2019) lahan pengembangan kopi Arabika yang ditanami baru seluas 1.724,41 hektar. Kopi Arabika yang ditanam pada berada kelas kesesuaian lahan S2 (cukup sesuai) dan S3 (sesuai). Salah satu strategi utama dalam usaha pengembangan usahatani kopi Gayo adalah dengan meningkatkan mutu dan produksi kopi serta mitra memberikan harga kepada petani sesuai dengan peraturan yang berlaku (Utami \& Lily, 2017).

Kopi Arabika yang ada di Kabupaten Gayo Lues masih sangat berpotensi untuk dikembangkan. Dengan luasan pengembangan kopi yang cukup esar, dan merupakan salah satu kopi dengan cita rasa terbaik di dunia serta pangsa pasar yang menjanjikan, seharusnya kopi Arabika di Kabupaten Gayo Lues dapat menjadi mata pencaharian dan meningkatkan pendapatan serta kesejahteraan para petaniBerdasarkan (Badan Pusat Statistik, 2018), persentase penduduk miskin di Kabupaten Gayo Lues, menempati peringkat kedua di Provinsi Aceh setelah Kabupaten Aceh Singkil. Dengan Garis Kemiskinan Rp. 368.583 per Kapita per bulan. Sehingga perlu dilakukan kajian analisis skala usaha dan finansial usaha tani kopi Arabika $\mathrm{n}$ di Kabupaten Gayo lues, untuk dapat mengetahui luasan lahan yang diperlukan oleh petani untuk dapat memenuhi hidup layak sesuai dengan kebutuhan hidup layak (KHL) di
Kabupaten Gayo Lues (Tania et al., 2019).

\section{METODE PENELITIAN}

Penelitian dilaksanakan di Kabupaten Gayo Lues, metode penelitian yang digunakan adalah metode deskriptif, yang merupakan suatu metode penelitian dalam meneliti data-data yang dikumpulkan, disusun, dijelaskan, serta dianalisis. Metode pengambilan sampel dilakukan secara purposive sampling yang disesuaikan dengan kelas kesesuaian lahan (Mulyana, 2019) dengan jumlah data yang diambil Petani sebanyak 45 responden serta Pedagang sebanyak 10 responden.

Metode penghitungan skala usaha luas lahan dan produksi dianalisis dengan menggunakan pendekatan BEP (Break Event Point), telah digunakan oleh (Indra, 2011) dalam menghitung skala usaha pada usahatani kopi arabika dan (Bagio et al., 2020) pada usahatani kelapa sawit. Ada 3 pendekatan BEP yaitu:

* BEP volume produksi = total biaya produksi (Rp/kg) ... 1) harga jual (Rp)

BEP harga poduksi = total biaya produksi (Rp)...........2) total produksi $(\mathrm{kg})$

* BEP luas lahan = BEP volume produksi (kg) .......3) Jumlah produksi/ha

Untuk menghitung kelayakan finansial usahatani kopi arabika dapat dilakukan dengan menggunakan beberapa indikator pendekatan atau alat analisis (Kadariah, 2001). Pendekatan analisis kelayakan 
finansial juga digunakan oleh beberapa peneliti seperti (Zakaria, 2019), dan (Wahyuni et al., 2012).

Untuk kelayakan finansial usahatani kopi Arabika dapat dilakukan dengan menggunakan beberapa indikator pendekatan atau alat analisis sebagai berikut:

1. Net Present Value (NPV)

$$
\left.\mathrm{NPV}=\sum_{t=0}^{n} \frac{(\mathrm{Bt}-\mathrm{Ct})}{(1+\mathrm{i}) \mathrm{t}} \ldots 4\right)
$$

Keterangan :

Bt adalah penerimaan atau benefit tahun ke $\mathrm{t}(\mathrm{Rp} / \mathrm{kg})$;

$\mathrm{Ct}=$ biaya atau cost pada tahun ke t;

$\mathrm{N}$ = lamanya periode waktu;

I = suku bunga kredit petani pada tahun penelitian (2019).

2. Internal Rate of Return (IRR)

$\left.\mathrm{IRR}=i_{0}+\left(i_{1}-i_{0}\right) \frac{N P V}{N P V_{0}-N P V_{1}} . .5\right)$

Keterangan :

io = Tingkat bunga yang berlaku di pasar modal (opportunity cost of capital);

$i_{1} \quad=$ Tingkat bunga pembanding (discount rate pembanding);

$\mathrm{NPV}_{0}=$ NPVpada $i_{0} ;$

$\mathrm{NPV}_{1}=\mathrm{NPV}$ pada $i_{1}$

3. Payback Period (PP)

$P P=t+\frac{c}{b} x 1$ tahun ...6)

Keterangan:

$$
\begin{aligned}
P P= & \text { Payback Period } \\
t= & \text { tahun terakhir dimana } \\
& \text { jumlah net cash flow } \\
& \text { kumulatif belum menutupi } \\
& \text { nilai investasi } \\
b= & \text { selisih dari nilai kumulatif } \\
& \text { net cash flow pada tahun } \\
& \text { ke-t dengan nilai investasi }
\end{aligned}
$$
$c=$ nilai net cash flow pada tahun ke- $(\mathrm{t}+1)$ atau saat PBP berada

4. Analisis Nilai Pengganti (Switching Value), Analisis switching value digunakan untuk memperhatikan dampak perubahan dari suatu variabel terhadap hasil analisis kelayakan.

\section{HASIL DAN PEMBAHASAN}

Skala luasan lahan usahatani kopi arabika yang perlu digarap oleh petani supaya petani mendapatkan pendapatan yang layak sehingga dapat menghidupi keluarga. Untuk itu perlu dihitung titik impas pulang pokok atau Break Event Point, baik itu BEP berdasarkan jumlah produksi kopi arabika, harga jual serta luas lahan minimal yang layak untuk dibudidayakan.

$>$ BEP Berdasarkan Jumlah Produksi

$$
\begin{aligned}
& \text { BEP Jumlah Produksi }= \\
& \frac{32.619 .130,48}{35.444,44}=920,29 \mathrm{~kg} / \\
& \text { tahun }
\end{aligned}
$$

$>$ BEP Berdasarkan Harga Jual (Rp)

$$
\begin{aligned}
& B E P_{\text {Harga Jual }}= \\
& \frac{32.619 .130,48}{1.891,67}=17.243,59 \mathrm{Rp} / \\
& \mathrm{kg}
\end{aligned}
$$

BEP Luas lahan garapan (farm size)

Titik Impas Luas Lahan = $\frac{920,29}{1.891,67}=0,49 \mathrm{Ha}=4.864,96 \mathrm{M}^{2}$

Berdasarkan analisis yang dilakukan, dengan luas lahan 0,49 ha atau 4.864,96 $\mathrm{m}^{2}$ petani kopi sudah mencapai titik impas dalam 
mengusahakan usahatani kopi. Dengan rata-rata pendapatan pertahun Rp. 33.619.000 atau bila dihitung rata-rata perbulan per hektar akan memberikan pendapatan sebesar Rp. 2.801.583. Apabila besarnya keluarga ada sebanyak 5 (lima) orang atau jumlah tanggungan sebesar 4 (empat) orang dengan masing-masing Rp. 560.317 per orang, sementara itu di daerah penelitian sebanyak 64 persen responden memiliki jumlah tanggungan 3-5 orang. Maka usahatani kopi arabika perhektar perpetani sudah dapat memenuhi kebutuhan hidup keluarga untuk menjadi keluarga yang kehidupannya diatas garis kemiskinan dan dapat dinyatakan sebagai keluarga sejahtera. Bila dilihat dari tingkat garis kemiskinan di Kabupaten Gayo Lues Rp. 368.583 per bulan, jadi dapat dikatakan bahwa petani kopi arabika sejahtera. Sejalan dengan penelitian (Indra, 2011) titik impas luas lahan adalah 0,69 ha. Artinya usahatani kopi akan memperoleh keuntungan jika luas lahan usahataninya diatas 0,69 ha.

Tabel 1. Rata-rata Hasil Finansial Usahatani Kopi Arabika Kabupaten Gayo Lues

\begin{tabular}{|c|c|c|c|}
\hline No & Kriteria & Indikator & Keterangan \\
\hline 1 & Net Present Value & Rp. 83.267.995 & Layak \\
\hline 2 & Net $B / C$ & 2,24 & Layak \\
\hline 3 & IRR & 21,42 persen & Layak \\
\hline 4 & PBP & $\begin{array}{r}9,79 \\
\text { hun } 9 \text { bulan } 14 \text { hari }\end{array}$ & Layak \\
\hline
\end{tabular}

Sumber: Data Primer (diolah), 2020

Selanjutnya untuk BEP jumlah produksi kopi, dalam satu tahun dengan biaya yang dikeluarkan maka petani sudah pulang pokok pada produksi sebanyak 920,29 kg/tahun, sedangkan pada lokasi penelitian ratarata produksi kopi $7.567 \mathrm{Kg}$. Harga kopi bervarisi antara Rp. 25.000 sampai dengan Rp. 50.000 per kg dengan rata-rata harga jual untuk kopi gabah didaerah penelitian sebesar Rp. 35.444,44 per kg. harga jual ini berbeda tergantung grade kopinya dimana penentu harga adalah pedagang pengumpul. Berdasarkan analisis pada harga Rp. 17.243,59 per $\mathrm{kg}$ petani sudah bisa menutupi semua biaya yang dikeluarkan untuk usahatani kopi arabika.

Sejalan dengan penelitian (Zakaria, 2019), hasil perhitungan BEP diketahui bahwa titik impas untuk usaha tani kopi arabika pada penjualan senilai Rp. 18.274.000 atau dapat juga dikatakan bahwa diperlukan penjualan sebesar 794,521 Kg gabah kering kopi arabika untuk mendapatkan kondisi seimbang antara biaya dengan keuntungan. Selanjutnya penelitian (Indra, 2011) Untuk pengembalian modal usahatani kopi per hektar di Aceh Tengah apabila penerimaan mencapai sebesar Rp. 6.006.657,78. Jika harga kopi 
yang berlaku adalah Rp. 13.000/kg, maka Titik Impas volume produksi $462,05 \mathrm{~kg} / \mathrm{ha} / \mathrm{th}$. Begitu juga penelitian yang dilakukan oleh (Amir et al., 2017), pendapatan usahatani petani kopi sebesar Rp 5.816.640,/hektar/tahun dengan keuntungan sebesar Rp 2.770.612 per tahun dan berdasarkan hasil perhitungan R/C Rasio yaitu 1,9 layak untuk diusahakan.

Analisis kelayakan finansial dapat dilihat dari keempat kriteria kelayakan investasi melalui perolehan nilai NPV, Net B/C, IRR, dan payback periode. Berikut hasil perhitungan analisis kelayakan finansial untuk usahatani kopi arabika di Kabupaten Gayo Lues selama dua puluh tahun.

Berdasarkan analisis finansial bahwa usahatani kopi arabika di Kabupaten Gayo Lues dengan nilai NPV > 0 sebesar Rp. 83.267.995,mengambarkan bahwa usahatani kopi arabika di Kabupaten Gayo Lues layak untuk diusahakan. Net Present Value yang sama dengan Rp. 83.267.995,menunjukkan manfaat bersih yang diterima petani selama menjalankan usahatani kopi arabika sesuai dengan umur tanaman yaitu 20 tahun terhadap tingkat diskon (discount rate) yang berlaku (tingkat suku bunga sebesar 12\%) dimana umur tanaman sekitar 20 tahun. Selain NPV, kriteria lain yang dianalisis adalah nilai Net B/C > 0 yaitu sebesar 2,24 yang artinya, setiap satu rupiah yang dikeluarkan selama umur usaha menghasilkan Rp. 2,24 satuan manfaat bersih.
Nilai IRR yang diperoleh dari usahatani kopi arabika di Kabupaten Gayo Lues adalah 21,79 persen dimana nilai IRR lebih besar dibandingkan dengan nilai discount rate yang berlaku yaitu sebesar 12 persen sehingga berdasarkan nilai IRR usahatani layak untuk diusahakan. Selanjutnya untuk periode pengembalian biaya investasi dapat diperoleh pada saat umur tanaman mencapai 9 tahun 9 bulan 14 hari. Berdasarkan hasil keempat kriteria tersebut, maka usahatani kopi arabika di Kabupaten Gayo Lues layak untuk dijalankan.

Kabupaten gayo Lues merupakan daerah yang sangat sesuai untuk penanaman kopi, dimana kopi yang berasal dari daerah ini sudah sangat terkenal. Kondisi wilayah yang berada di dataran tinggi dan kemampuan petani dalam mengolah usaha taninya sudah sangat baik dikarenakan budidaya kopi di daerah ini sudah turun temurun.

Sejalan dengan penelitian (Zakaria, 2019), dari hasil analisis kelayakan finansial didapat penerimaan/ pendapatan bersih sebesar Rp. 4.693.625 dalam setiap hektar lahan yang dikelola, dengan tingkat suku bunga 14\% diperoleh nilai NPV positif sebesar Rp. 9.104.913,375. Berdasarkan analisis perhitungan diperoleh nilai Net B/C Ratio 2,067. Nilai IRR usaha tani kopi arabika diperoleh IRR 25.81\% dimana nilai ini lebih besar dari suku bunga bank komersial yang berlaku, yaitu $14 \%$. Begitu juga penelitian yang 
dilakukan oleh (Kusmiati \& Nursamsiyah, 2015) terkait kelayakan Usahatani kopi arabika. Secara finansial usahatani kopi arabika di Desa Karangpring Kecamatan Sukorambi Kabupaten Jember layak untuk diusahakan dengan nilai NPV positif sebesar Rp. 3.690.704; nilai Net B/C sebesar 1,5; IRR sebesar 34,38\%; dan jangka pengembalian modal adalah 3 tahun 10 bulan 24 hari dengan tingkat suku bunga kredit koperasi petani Desa Karangpring sebesar 24\%.

Berdasarkan beberapa penelitan yang terkait agroindustri pengolahan kopi arabika dalam menciptakan nilai tambah sudah efesien (Epaga et al., 2019). Selanjutnya efisiensi pemasaran ekspor kopi arabika dinilai efisien yaitu sebesar (EP 0-50\% efisiensi pemasaran) (Baihaqi et al.,
2020). Maka dari itu, usahatani kopi arbika mempunyai prospek yang sangat menjanjikan.

Beberapa asumsi yang digunakan dalam analisis switching value pada usahatani kopi arabika di Kabupaten Gayo Lues antara lain:

a. Biaya operasional naik 10 persen, dikarenakan harga beli dari inputinput produksi mengalami kenaikan, namun harga jual biji kopi arabika tetap (konstan/tidak berubah).

b. Penerimaan dari usaha tani kopi arabika mengalami penurunan sebesar 10 persen, yang dapat diakibatkan seperti produksi yang menurun akibat tanaman diserang hama penyakit, harga jual biji kopi turun ditingkat petani.

Tabel 2. Hasil Perhitungan Analisis Switching Value pada Usahatani Kopi Arabika di Kabupaten Gayo Lues

\begin{tabular}{|c|c|c|c|c|}
\hline \multirow[b]{2}{*}{ No } & \multicolumn{4}{|c|}{ Analisis Switching Value } \\
\hline & Kriteria & $\begin{array}{c}\text { Biaya Naik } \\
10 \%\end{array}$ & $\begin{array}{c}\text { Penerimaan } \\
\text { Turun } 10 \%\end{array}$ & Ket \\
\hline 1 & Net Present Value & Rp. 64.043 .609 & Rp. 49.541.072 & Layak \\
\hline 2 & Net B/C & 1,93 & 1,72 & Layak \\
\hline 3 & IRR & 19,37 & 17,99 & Layak \\
\hline 4 & PBP & 10,48 & 11,81 & Layak \\
\hline & & $\begin{array}{r}10 \text { tahun } 11 \text { bulan } 12 \\
\text { hari }\end{array}$ & $\begin{array}{r}11 \text { tahun } 10 \text { bulan } \\
22 \text { Hari }\end{array}$ & \\
\hline
\end{tabular}

Sumber: Data Primer (diolah), 2020

Dari hasil analisis switching value diketahui bahwa batas optimal perubahan nilai yang dapat mempengaruhi komponen inflow seperti peningkatan biaya operasional seperti kenaikan upah tenaga kerja dan biaya produksi. Hasil analisis dengan kenaikan 10 persen biaya operasional usaha tani kopi arabika masih layak. Sedangkan bila dilihat dari penerimaan usahatani menurun sebesar 10 persen usaha tani kopi arabika masih layak untuk diusahakan.

Berdasarkan analisis kelayakan finansial, usahatani kopi arabika layak 
untuk dilakukan, namun demikian perlu juga diperhatikan beberapa alternatif strategi yang dapat dilakukan dalam usaha pengembangan usahatani kopi Gayo adalah sebagai berikut : 1) Meningkatkan mutu dan produksi kopi serta mitra memberikan harga kepada petani sesuai dengan peraturan yang berlaku 2) Memperluas jaringan pemasaran dengan cara memanfaatkan organisasi - organisasi petani serta penggunaan tekhnologi dan Informasi 3) Membentuk Lembaga Penelitian serta lembaga keuangan agar dapat bersaing di pasar bebas (Utami \& Lily, 2017).

\section{SIMPULAN}

Dengan Luas lahan 0,49 ha atau $4.864,96 \mathrm{~m}^{2}$ petani kopi arabika sudah mencapai titik impas dalam mengusahakan usahataninya. Produksi kopi arabika sebesar 920,29 $\mathrm{kg} /$ tahun maka petani sudah pulang pokok pada produksi. Serta harga Rp. 17.243,59 per kg petani sudah bisa menutupi semua biaya yang dikeluarkan untuk usahatani kopi arabika. Rata-rata pendapatan per bulan per hektar sebesar Rp. 2.801.583. Nilai ini sudah berada di atas garis kemiskinan di Kabupaten Gayo Lues yaitu Rp. 368.583 per bulan. Pada tingkat suku bunga sebesar $12 \%$ nilai Net $\mathrm{B} / \mathrm{C}>0$ yaitu sebesar 2,24 artinya, setiap satu rupiah yang dikeluarkan selama umur usaha menghasilkan Rp. 2,24 satuan manfaat bersih.

\section{DAFTAR PUSTAKA}

Amir, N. H., Elly Rasmikayati, \& Saefudin, B. R. (2017). Analisis Usahatani Kopi Di Kelompok Tani Hutan Giri Senang Desa Giri Mekar Kabupaten Bandung. Jurnal Ilmiah Mahasiswa AGROINFO GALUH, 4(3), 472-479.

Anhar, A., Widayat, H. P., Muslih, A. M., Subhan, S., Romano, R., Baihaqi, A., Bahri, T. S., Zulkarnain, Z., Bagio, B., Yusmaizal, Y., \& Abubakar, Y. (2020). Evaluation of Farmers Management Practices of Arabica Coffee Plantation Across Altitude for Climate Change Adaptation Strategies in Aceh, Indonesia. Aceh International Journal of Science and Technology, 9(2), 75-82. https://doi.org/10.13170/aijst.9.2. 17375

Arlius, F., Tjandra, M. A., \& Yanti, D. (2017). Analisis Kesesuaian Lahan Untuk Pengembangan Komoditas Kopi Arabika Di Kabupaten Solok. Jurnal Teknologi Pertanian Andalas, 21(1), 70. https://doi.org/10.25077/jtpa.21.1. 70-78.2017

Badan Pusat Statistik. (2018). Kabupaten Gayo Lues dalam Angka 2018. BPS Kabupaten Gayo Lues.

Bagio, B., Handayani, S., Nasution, A., \& Zulkarnain, Z. (2020). Analisis Pendapatan Usahatani Kelapa Sawit Di Trans Bakal Buah Kota Subulussalam. Ekombis, 6(2), 158164.

https://doi.org/10.35308/ekombis. v6i2.2880

Baihaqi, A., Hamid, A. H., Susanti, E., Paga, P. E., Wardhana, M. Y., \& Marsudi, E. (2020). Analysis of value added agro industry arabica export coffee processing in Aceh Tengah case study at Oro Coffee Gayo. IOP Conference Series: Earth and Environmental Science, 425(1). https://doi.org/10.1088/17551315/425/1/012076

Ellyanti, E., Karim, A., \& Basri, H. (2012). Analisis Indikasi Geografis Kopi Arabika Gayo Ditinjau Dari Rencana 
Tata Ruang Wilayah Kabupaten. Jurnal Agrista Unsyiah, 16(2), 46-61.

Epaga, P., Baihaqi, A., Susanti, E., \& Muji, B. (2019). Analisis nilai tambah agroindustri pengolahan kopi arabika ekspor di kabupaten aceh tengah (studi kasus pada ksu sara ate) 1. Jurnal Agribisnis Dan Sosial Ekonomi Pertanian UNPAD, 4(1), 602-611.

Indra. (2011). Penentuan Skala Usaha Dan Analisis Efisiensi Ekonomi Usahatani Kopi Rakyat Di Kabupaten Aceh Tengah. Jurnal Agrisep, 12(1), 15-22.

https://doi.org/10.24815/agrisep.v $12 \mathrm{i} 1.206$

Izzati, R., Karim, A., Arabia, T., Hifnalisa, H., Manfarizah, M., Syakur, S., \& Hafid, I. (2019). of Advanced Research Teaching Professionalism By Vignettes in Psychiatry for Nursing Students. International Journal of Advanced Research, 7(6), 461-468.

https://doi.org/10.21474/IJAR01

Kadariah. (2001). Evaluasi Proyek Analisis Ekonomi. Lembaga Penelitian Fakultas Ekonomi UI.

Karim, A., Sugianto, S., Fazlina, Y. D., Rusdi, M., Manfarizah, M., \& Hifnalisa, H. (2020). Land Arrangement for Citronella (Cymbopogon Nardus) and Arabica Coffee in the Cultivation Area in Gayo Lues District, Aceh Province Indonesia: A Land Suitability Approach. Aceh International Journal of Science and Technology, 9(3), 207-215. https://doi.org/10.13170/aijst.9.3. 18495

Kusmiati, A., \& Nursamsiyah, D. Y. (2015). Kelayakan Finansial Usahatani Kopi Arabika dan Prospek Pengembangannya di Ketinggian Sedang. Agriekonomika, 4(2), 221234.
Mawardo, S., Hulupi, R., Wibawa, A., Wiryaputra, S., \& Yusianto. (2008). Panduan Budidaya dan Pengolahan Kopi Arabika Gayo. Aceh Kopi Forum. Tania, R., Widjaya, S., \& Suryani, A. (2019). Usahatani, Pendapatan Dan Kesejahteraan Petani Kopi Di Lampung Barat. Jurnal Ilmu-Ilmu Agribisnis, $\quad 7(2), \quad 149$. https://doi.org/10.23960/jiia.v7i2. 149-156

Utami, K. F., \& Lily. (2017). Strategi Pengembangan Usaha Tani Kopi Arabica (COFFEA SP) Di Kabupaten Gayu. Jurnal Teknologi Dan Industri Pangan, X(8), 47-59.

Wahyuni, S. S., Utama, S. P., \& Mulyasari, G. (2012). Analisis Kelayakan Finansial Usahatani Kopi Arabika Di Desa Bandung Baru Kecamatan Kabawetan Kabupaten Kepahiang. Jurnal AGRISEP, 11(1), 43-50. https://doi.org/10.31186/jagrisep. 11.1.43-50

Widayat, H. P., Anhar, A., \& Baihaqi, A. (2015). Dampak Perubahan Iklim Terhadap Produksi, Kualitas Hasil Dan Pendapatan Petani Kopi Arabika Di Aceh Tengah. Agrisep, 16(2), 816.

Zakaria, A. (2019). Analisis Kelayakan Finansial Usaha Tani Kopi Arabika (Coffea arabica) Di Desa Suntenjaya, Kecamatan Lembang Kabupaten Bandung Barat. Agroscience (Agsci), 9(1), 34. https://doi.org/10.35194/agsci.v9i 1.633

Zulkarnain, Z., Rahmaddiansyah, R., Alpian, R., \& Bagio, B. (2020). Perbandingan Tingkat Produktivitas Dan Pendapatan Petani Kopi Arabika Yang Melakukan Teknik Pemangkasan Rutin Dan Yang Tidak Di Kecamatan Bener Kelipah. Agrifo, 5(1), 78-86. https://doi.org/10.29103/ag.v5i1.3 215 